\title{
Radio y cultura: una propuesta de radio ciudadana en Internet ${ }^{1}$
}

\author{
Mauricio Andrés Álvarez-Moreno² \\ Sandra Catalina Vásquez-Carvajal ${ }^{3}$
}

Recibido: 2014-09-26

Enviado a pares: 2014-10-06
Aprobado por pares: 2014-11-30

Aceptado: 2015-01-22

DOI: 10.5294/pacla.2015.18.2.7

\section{Para citar este artículo / To reference this article / Para citar este artigo}

Álvarez-Moreno, M.A., Vásquez-Carvajal, S.C. Junio de 2015. Radio y cultura: una propuesta de radio ciudadana en Internet. Palabra Clave 18(2), 475-498. DOI: 10.5294/ pacla.2015.18.2.7

\section{Resumen}

El presente artículo es resultado de la investigación para optar a título de magíster "La Peña Cultural: modelo de radio ciudadana en Internet", realizada durante los años 2013 y 2014 para la Universidad de Medellín. En ella se realiza una exploración de la radio en Internet como plataforma con herramientas multimediales que podrían afianzar la formación de ciudadanía reflexiva por medio de contenidos de promoción cultural. De la misma manera, identifica, a partir de un rastreo de emisoras en Colombia, cómo esas herramientas -las redes sociales, podcasts, chats, canales de video y nuevas formas comunicativas- permiten la participación activa de los ciudadanos en su producción.

\footnotetext{
1 Artículo proveniente del proyecto de investigación "Caracterización de modelos de radio en Internet que desarrollan contenidos culturales en Colombia”, matriculado en el banco de proyectos de la Universidad de Medellín.

2 Comunicador y relacionista corporativo de la Universidad de Medellín. Magíster en Comunicación Educativa, Universidad Tecnológica de Pereira. Máster en Relaciones Internacionales, Universidad Rey Juan Carlos. Profesor de tiempo completo, Facultad de Comunicación de la Universidad de Medellín. Coordinador del Centro de Investigación en Comunicación. maualvarez@udem.edu.co

3 Comunicadora social, candidata a magíster en comunicación, Universidad de Medellín. Gestora social y cultural en Parque Biblioteca José Horacio Betancur, San Antonio de Prado, Medellín. catac180@gmail.com
} 
Rescatar el uso de tecnologías que facilitan la comunicación, como la radio en Internet, para reconocer y recuperar el valor de la promoción cultural propia de un estado en aras de la formación de una ciudadanía reflexiva, es el acercamiento que se hizo a partir de la etnografía y la investigación aplicada y que ahora se expone en este artículo. Es la forma en que los ciudadanos podrían converger en un medio de comunicación para producir contenidos que fortalezcan su identidad cultural o, si se quiere, su visión de nación. Es la apuesta por establecer una alternativa a los ya tradicionales modelos, una guía para la comunidad interesada en promover una ciudadanía reflexiva del patrimonio cultural.

\section{Palabras clave}

Radio cultural, ciudadanía, participación, radio en Internet (fuente: Tesauro de la Unesco). 


\section{Radio and Culture: A Proposed Citizens' Internet Radio}

\section{Abstract}

This article is the result of research project to qualify for a Master's degree "La Peña Cultural: model citizen Internet radio" carried out during 2013 and 2014 for Universidad de Medellin. It explored the Internet radio as a platform with multimedia tools that could strengthen the formation of reflective citizenship through content of cultural promotion. Similarly, it identifies, from a tracking station in Colombia, how these tools -social networks, podcasts, chats, video channels and new ways to communicate- allow the active participation of citizens in their production.

Rescuing the use of technologies that facilitate communication, such as Internet radio, to recognize and retrieve the value of their own cultural promotion of a state in order to form a reflective citizenship, it is the approach that was made from the ethnographic and applied research and is now presented in this article. It is the way in which citizens could converge in a medium to produce content that will strengthen their cultural identity or, if you will, their vision of the nation. It is a commitment to establish an alternative to the traditional models, a guide to the community interested in promoting a reflexive citizen of cultural heritage.

\section{Keywords}

Cultural radio, citizenship, participation, Internet radio (Source: Unesco Thesaurus). 


\section{Rádio e cultura: uma proposta de rádio cidadã na internet}

\section{Resumo}

O presente artigo é resultado da pesquisa "A 'Penha Cultural: modelo de rádio cidadã na internet" para receber o título de mestre, realizada durante 2013 e 2014, na Universidade de Medellín (Colômbia). Nela, realiza-se uma exploração da rádio na internet como plataforma com ferramentas multimidiáticas que poderiam consolidar a formação de cidadania reflexiva por meio de conteúdos de promoção cultural. Da mesma forma, identifica, a partir de uma investigação de emissoras na Colômbia, como essas ferramentas - as redes sociais, podcasts, chats, canais de vídeo e novas formas comunicativas - permitem a participação ativa dos cidadãos em sua produção.

Resgatar o uso de tecnologias que facilitam a comunicação, como a rádio na internet, para reconhecer e recuperar o valor da promoção cultural própria de um estado em vias da formação de uma cidadania reflexiva, é a aproximação que se fez a partir da etnografia e a pesquisa aplicada e que agora se expõe neste artigo. É a forma em que os cidadãos que fortalecem sua identidade cultural ou sua visão de nação. É a aposta por estabelecer uma alternativa aos já tradicionais modelos, um guia para a comunidade interessada em promover uma cidadania reflexiva do patrimônio cultural.

\section{Palavras-chave}

Rádio cultural, cidadania, participação, rádio na internet (Fonte: Tesauro da Unesco). 


\section{Presentación}

"La Peña Cultural: modelo de radio ciudadana en Internet" es un proyecto de investigación que se desarrolla partiendo de la hipótesis de que un modelo para radios de este tipo, que aborde contenidos de promoción cultural, ${ }^{4}$ podría contribuir a la formación de ciudadanía reflexiva, en tanto es un medio propicio para la producción de contenidos por parte de quienes, en el formato tradicional, ${ }^{5}$ serían los receptores de los mismos. La radio en Internet $^{6}$ se ha configurado como una plataforma multimedial ${ }^{7}$ cuyos componentes (redes sociales, podcasts, chats, canales de video y nuevas formas comunicativas) "se optimizan en la interactividad con el receptor, quien pasa de ser un agente pasivo a ser un agente activo en el proceso de comunicación” (García González, 2010: 138). En palabras de Sánchez Torres (1994: 38), la radio en Internet sería un canal apropiado para la participación y "su multiplicación permite la combinación de formas directas e indirectas de intervención ciudadana”.

Este proyecto investigativo se hizo para hallar los componentes de una ruta metodológica para establecer el tratamiento de contenidos de promoción cultural de la radio en Internet que apunten a la formación de ciudadanía reflexiva. En este sentido, trató de encontrar y evidenciar en el uso de la plataforma tecnológica en Colombia, y las herramientas para esta formación de ciudadanía a través de la promoción cultural. Sin embargo, esta búsqueda comprobó la baja implementación de este medio, además de la poca o nula participación de los ciudadanos para producir contenidos que alimenten su identidad cultural. Por eso, el modelo definido a partir de ella debió comprender los elementos de los que se compone este tipo de radio y los contenidos que algunas emisoras desarrollan -análogas llevadas a Internet, como se encontraron- para caracterizar bajo la teoría de una

4 La promoción cultural se encuentra ligada a las políticas públicas, reconociendo la importancia que tienen en la formación de ciudadanos con sentido de pertenencia y participativos de las apuestas artísticas y culturales.

5 El formato tradicional es la radio análoga.

6 Con radio en Internet se hace referencia sobre aquella que combina streamcasting y podcasting de audio en sus plataformas. El investigador la ha asumido como aquella que tiene la posibilidad de transmitir y alojar contenidos a través de una plataforma en Internet, aunque el concepto radio provenga precisamente de la transmisión de contenidos por vía de ondas hertzianas.

7 Se refiere a que la plataforma en Internet se compone de múltiples medios para la exposición de contenidos: videos, podcasts, fotografías, chats y redes sociales. 
ciudadanía reflexiva ${ }^{8}$ unos componentes radiales que, trabajados desde la promoción cultural, contribuyan a su formación. Esto implicó pensar que las características de la radio en Internet, sumadas a la promoción cultural, impulsarían la participación activa de oyentes en la producción de contenidos, y en esta nueva era, "uno de los retos es la formación o el desarrollo de ciertas competencias - cognitivas, comunicativas, sensibles, culturalespara actuar no solo profesionalmente en la era de la información sino para generar un verdadero empoderamiento" (Valderrama, 2004: 20).

\section{Metodología}

Es importante resaltar que este proyecto se asumió desde dos métodos: el primero, la etnografía, dio los elementos para el diseño y la aplicación de las fichas de contenido necesarias en el desarrollo de la ruta metodológica; el segundo, la investigación aplicada, sirvió para generar, a partir del análisis de los hallazgos y a la luz de la teoría el modelo o producto final del proyecto.

La ruta metodológica se compuso de tres fases. La primera de ellas tuvo como objetivos caracterizar los modelos de radio en Internet que desarrollen contenidos culturales en Colombia y verificar si ellos contribuyen a la formación de ciudadanía reflexiva.

En el rastreo se hizo uso de los buscadores de la web para realizar una búsqueda detallada de las radios colombianas que desarrollan contenidos culturales. Se hallaron tres diferentes rutas de Internet que agrupan a las emisoras que trabajan contenidos culturales en Colombia. ${ }^{9}$ Estas rutas permitieron encontrar, ya clasificadas como culturales, a aquellas emisoras de interés público, comerciales y universitarias que se necesitaban para aplicar el instrumento.

8 El concepto de ciudadano reflexivo es propuesto por Carlos Thiebaut en su obra Vindicación del ciudadano (1998: 169), por medio de la cual establece que "El ciudadano es, tiene que ser, un activo sujeto reflexivo, capaz de operar con diversidad de lógicas en distintos sistemas de acción: su concepción de lo público ha de estar marcada por una acendrada tolerancia; ha de adoptar una actitud reflexiva con respecto a lo que cree como condición para asumir sus responsabilidades".

9 Las url identificadas para rastrear la muestra final fueron:

a) http://www.colombia.com/radio/g3/emisoras-colombiana

b) http://www.radiouniversitaria.org/

c) http://www.radioscolombia.com/radiostation-listing-genre $\% 7 \mathrm{C}=\% 7 \mathrm{CCulturales} / 0 / \mathrm{pre} . \mathrm{html} /$ 


\section{Cuadro 1}

\section{Fase 1, primer objetivo. Ruta metodológica del proyecto}

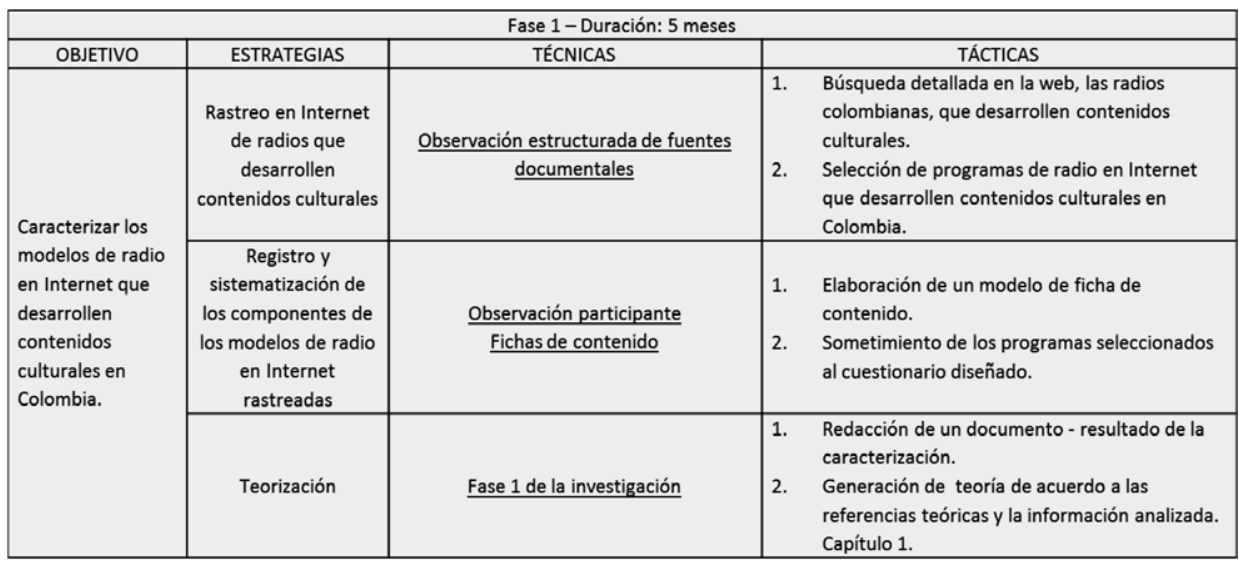

\section{Cuadro 2}

\section{Fase 1, segundo objetivo. Ruta metodológica del proyecto}

\begin{tabular}{|c|c|c|c|}
\hline \multirow{3}{*}{$\begin{array}{l}\text { Verificar si los } \\
\text { modelos de radio } \\
\text { en Internet que } \\
\text { desarrollan } \\
\text { contenidos } \\
\text { culturales } \\
\text { contribuyen a la } \\
\text { formación de } \\
\text { ciudadania } \\
\text { reflexiva }\end{array}$} & $\begin{array}{l}\text { Registro y } \\
\text { sistematización de los } \\
\text { componentes de los } \\
\text { modelos de radio en } \\
\text { Internet rastreadas }\end{array}$ & $\frac{\text { Observación estructurada }}{\underline{\text { Fichas de contenido }}}$ & $\begin{array}{l}\text { 1. Elaboración de un modelo de ficha de contenido. } \\
\text { 2. Sometimiento de los programas caracterizados } \\
\text { como aquellos que desarrollan contenidos } \\
\text { culturales al cuestionario diseñado. }\end{array}$ \\
\hline & $\begin{array}{l}\text { Comprobar si los } \\
\text { programas } \\
\text { seleccionados forman } \\
\text { ciudadanía reflexiva }\end{array}$ & $\frac{\text { Observación participante }}{\underline{\text { Análisis comparativo }}}$ & $\begin{array}{l}\text { 1. Mecanismos de participación. } \\
\text { 2. Modos de participación. } \\
\text { 3. Direccionalidad de la información que se publica } \\
\text { en el medio. }\end{array}$ \\
\hline & $\begin{array}{c}\text { Registro y } \\
\text { sistematización }\end{array}$ & Fichas de contenido & $\begin{array}{l}\text { 1. Registro de la información obtenida del análisis } \\
\text { comparativo. } \\
\text { 2. Generación de resultados de acuerdo a las } \\
\text { referencias teóricas y a la información registrada. }\end{array}$ \\
\hline
\end{tabular}

Seguidamente se seleccionaron los programas de radio en Internet que desarrollan contenidos culturales en Colombia, los cuales pertenecen a siete emisoras de las 110 revisadas, y se procedió a elaborar un modelo de ficha de contenido para caracterizarlas, sometiendo los programas seleccionados al cuestionario diseñado. La ficha se compone de un encabezado, una primera parte "en cuanto a la forma", una segunda parte "en cuanto al contenido", un glosario de términos para esclarecer cómo se entienden para 
este proyecto y, por último, una nota aclaratoria de la referencia bibliográfica. La primera parte del instrumento aborda el tema de la forma; en otras palabras, se diseñó para que, por medio de la visualización de las plataformas y la navegación en ellas, se pudiesen rescatar los mecanismos de los que disponen para la participación de los oyentes y corroborar si tales mecanismos son usados por ellos.

\section{Cuadro 3 \\ Primera parte de la ficha de contenido 1}

\begin{tabular}{|c|c|c|c|c|c|c|c|}
\hline \multicolumn{8}{|c|}{ En cuanto a la forma } \\
\hline \multirow{2}{*}{$1 \mid \begin{array}{l}\text { ¿Con qué herramientas cuenta la } \\
\text { plataforma en la que se encuentra el } \\
\text { programa? }\end{array}$} & Chat & Video & Artículos & Galería & Redes sociales & Ninguna & Descripción \\
\hline & & & & & & & \\
\hline \multirow{2}{*}{$2 \begin{array}{l}\text { ¿Qué herramientas utilizan los } \\
\text { oyentes para participar en el } \\
\text { programa? }\end{array}$} & Chat & Video & Artículos & Galería & Redes sociales & Ninguna & Descripción \\
\hline & & & & & & & \\
\hline 3 ¿Cuál es el formato del programa? & Opinión & Informativo & Magazin & \multicolumn{2}{|c|}{ Dramatizado } & Documental & Descripción \\
\hline ¿Qué géneros utiliza el programa & Crónica & Reportaje & Noticia & Perfil & Informe & Entrevista & Descripción \\
\hline${ }^{4}$ para desarrollar los contenidos? & & & & & & & \\
\hline \multirow{2}{*}{$55 \begin{array}{l}\text { LQuiénes producen los contenidos } \\
\text { del programa? }\end{array}$} & \multirow{2}{*}{\multicolumn{2}{|c|}{ Staff de la emisora }} & \multirow{2}{*}{\multicolumn{2}{|c|}{ Expertos temáticos }} & Oyentes & \multirow{2}{*}{\multicolumn{2}{|c|}{ Otros ¿Quiénes? }} \\
\hline & & & & & & & \\
\hline
\end{tabular}

La segunda parte se enfocó en examinar el contenido que se presenta en los podcasts seleccionados, entendiendo que toda programación se encuentra planeada y direccionada a cumplir con unos propósitos que son trazados desde el deber ser de cada emisora como medio de comunicación.

\section{Cuadro 4 \\ Segunda parte de la ficha de contenido 1}

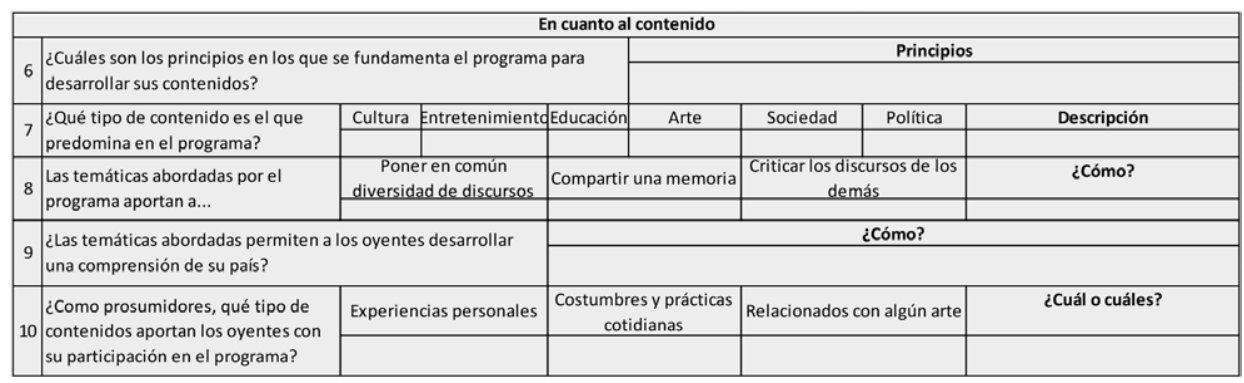


Continuando con la fase 1 del proyecto, se elaboró un segundo modelo de ficha de contenido para verificar la formación de ciudadanía reflexiva. Se sometieron a él los programas caracterizados como aquellos que desarrollan contenidos culturales y se verificaron los mecanismos y los modos de participación, además de la direccionalidad de la información que se publica en el medio, y, con la información registrada, se generaron algunos apuntes a manera de conclusiones, yendo siempre a las referencias teóricas.

\section{Cuadro 5 Ficha de contenido 2}

\begin{tabular}{|c|c|c|c|c|c|}
\hline \multicolumn{6}{|c|}{ Cuestionario } \\
\hline \multirow[b]{2}{*}{1} & \multirow{2}{*}{$\begin{array}{l}\text { ¿Las opiniones de los oyentes indican su } \\
\text { adhesión reflexiva a una identidad } \\
\text { colectiva? }\end{array}$} & Sí & No & & ¿Cómo? \\
\hline & & & & & \\
\hline \multirow[b]{2}{*}{2} & \multirow{2}{*}{$\begin{array}{l}\text { ¿Los oyentes que participan hacen uso } \\
\text { del hipertexto para argumentar sus } \\
\text { opiniones? }\end{array}$} & Sí & No & & ¿Cómo? \\
\hline & & & & & \\
\hline \multirow[b]{2}{*}{3} & \multirow{2}{*}{$\begin{array}{l}\text { ¿Los oyentes ejercen una participación } \\
\text { marcada por una acendrada tolerancia } \\
\text { hacia las opiniones de los demás? }\end{array}$} & Sí & No & & ¿Cómo? \\
\hline & & & & & \\
\hline \multirow[b]{2}{*}{4} & \multirow{2}{*}{$\begin{array}{l}\text { ¿Ejercen los oyentes su capacidad } \\
\text { reflexiva a través de los mecanismos de } \\
\text { participación que posee la emisora? }\end{array}$} & Sí & No & & ¿Cómo? \\
\hline & & & & & \\
\hline \multirow[b]{2}{*}{5} & \multirow{2}{*}{$\begin{array}{l}\text { Las opiniones de los oyentes apuntan a la } \\
\text { defensa y promoción de: }\end{array}$} & \multirow{2}{*}{\multicolumn{2}{|c|}{ Derechos sociales }} & Derechos políticos & Derechos culturales y raciales \\
\hline & & & & & \\
\hline \multirow[b]{2}{*}{6} & \multirow[b]{2}{*}{$\begin{array}{l}\text { De acuerdo a la pregunta anterior, ¿cómo } \\
\text { es la defensa de esos derechos? }\end{array}$} & \multicolumn{4}{|c|}{ Ejemplo de opinión expresada } \\
\hline & & & & & \\
\hline \multirow[b]{2}{*}{7} & \multirow{2}{*}{$\begin{array}{l}\text { En las opiniones expresadas se permiten } \\
\text { y visualizan: }\end{array}$} & \multicolumn{2}{|c|}{ Consenso } & Diálogo & Movilización \\
\hline & & & & & \\
\hline \multirow[b]{2}{*}{8} & \multirow[b]{2}{*}{$\begin{array}{l}\text { De acuerdo a la pregunta anterior, ¿cómo } \\
\text { se permiten y visualizan? }\end{array}$} & \multicolumn{4}{|c|}{ Ejemplo de opinión expresada } \\
\hline & & & & & \\
\hline \multirow[b]{2}{*}{9} & \multirow{2}{*}{$\begin{array}{l}\text { ¿Las opiniones de los oyentes giran en } \\
\text { torno a las temáticas planteadas por el } \\
\text { programa? }\end{array}$} & Sí & No & & ¿Cómo? \\
\hline & & & & & \\
\hline \multirow[b]{2}{*}{10} & \multirow{2}{*}{$\begin{array}{l}\text { ¿Las opiniones de los oyentes permiten } \\
\text { visualizar la sociedad plural a la que } \\
\text { pertenecen? }\end{array}$} & Sí & No & & ¿Cómo? \\
\hline & & & & & \\
\hline \multirow[b]{2}{*}{11} & \multirow[b]{2}{*}{$\begin{array}{l}\text { ¿Las opiniones que ejercen los oyentes se } \\
\text { fundamentan en discursos auténticos? }\end{array}$} & Sí & No & & ¿Cómo? \\
\hline & & & & & \\
\hline
\end{tabular}




\section{Cuadro 6 \\ Fase 2, ruta metodológica del proyecto}

\begin{tabular}{|c|c|c|c|}
\hline \multicolumn{4}{|c|}{ Fase 2 - Duración: 4 meses } \\
\hline OBJETIVO & ESTRATEGIAS & TÉCNICAS & TÁCTICAS \\
\hline \multirow{4}{*}{$\begin{array}{l}\text { Definir los } \\
\text { componentes para un } \\
\text { modelo de radio en } \\
\text { Internet que desde la } \\
\text { promoción cultural, } \\
\text { contribuya a la } \\
\text { formación de } \\
\text { ciudadanía reflexiva. }\end{array}$} & $\begin{array}{l}\text { Registro y } \\
\text { sistematización de los } \\
\text { componentes de los } \\
\text { modelos de radio en } \\
\text { Internet rastreadas }\end{array}$ & $\frac{\text { Observación estructurada }}{\underline{\text { Fichas de contenido }}}$ & $\begin{array}{l}\text { 1. Elaboración de un modelo de ficha de contenido. } \\
\text { 2. Sometimiento de los programas caracterizados } \\
\text { como aquellos que desarrollan contenidos } \\
\text { culturales al cuestionario diseñado. }\end{array}$ \\
\hline & $\begin{array}{c}\text { Comparar los } \\
\text { componentes de los } \\
\text { modelos de radios en } \\
\text { Internet que desarrollen } \\
\text { contenidos culturales y } \\
\text { contribuyan a la } \\
\text { formación de } \\
\text { ciudadania }\end{array}$ & $\frac{\text { Observación participante }}{\underline{\text { Análisis comparativo }}}$ & $\begin{array}{l}\text { 1. Categorización de los componentes para un } \\
\text { modelo de radio en Internet que contribuya a la } \\
\text { formación de ciudadanía. }\end{array}$ \\
\hline & $\begin{array}{c}\text { Registro y } \\
\text { sistematización }\end{array}$ & Memo analítico & $\begin{array}{ll}\text { 1. } & \text { Registro de la información obtenida del análisis } \\
\text { comparativo. } \\
\text { 2. }\end{array}$ \\
\hline & Teorización & Fase 2 de la investigación & $\begin{array}{l}\text { 1. Redacción de un documento - resultado de la } \\
\text { ficha. } \\
\text { 2. Capitulo } 3 .\end{array}$ \\
\hline
\end{tabular}

\begin{tabular}{|c|c|c|c|}
\hline OBJETIVO & ESTRATEGLAS & TÉCNICAS & TÁCTICAS \\
\hline \multirow{4}{*}{$\begin{array}{l}\text { Definir los componentes } \\
\text { para un modelo de radio } \\
\text { en internet que desde la } \\
\text { promoción cultural, } \\
\text { contribuya a la formación } \\
\text { de ciudadanía reflexiva. }\end{array}$} & $\begin{array}{l}\text { Registro y sistematización de } \\
\text { los componentes de los } \\
\text { modelos de radio en internet } \\
\text { rastreadas }\end{array}$ & $\begin{array}{c}\begin{array}{c}\text { Observación } \\
\text { estructurada } \\
\text { Fichas de contenido }\end{array} \\
\end{array}$ & $\begin{array}{l}\text { 1. Elaboración de un modelo de ficha de contenido. } \\
\text { 2. Sometimiento de los programas caracterizados como } \\
\text { aquellos que desarrollan contenidos culturales al cuestionario } \\
\text { diseñado. }\end{array}$ \\
\hline & $\begin{array}{l}\text { Comparar los componentes de } \\
\text { los modelos de radios en } \\
\text { internet que desarrollen } \\
\text { contenidos culturales y } \\
\text { contribuyan a la formación de } \\
\text { ciudadanía }\end{array}$ & $\begin{array}{c}\frac{\text { Observación }}{\text { participante }} \\
\text { Análisis comparativo }\end{array}$ & $\begin{array}{l}\text { 1. Categorización de los componentes para un modelo de radio } \\
\text { en internet que contribuya a la formación de ciudadanía. }\end{array}$ \\
\hline & Registro y sistematización & Memo analítico & $\begin{array}{l}\text { 1. Registro de la información obtenida del análisis comparativo. } \\
\text { 2. Generación de resultados de acuerdo a las referencias } \\
\text { teóricas y la información registrada. }\end{array}$ \\
\hline & Teorización & $\begin{array}{l}\text { Fase II de la } \\
\text { investigación }\end{array}$ & $\begin{array}{l}\text { 1. Redacción de un documento - resultado de la ficha. } \\
\text { 2. Capitulo } 3 .\end{array}$ \\
\hline
\end{tabular}

La segunda fase cumplió con el objetivo de definir los componentes para un modelo de radio en Internet que, desde la promoción cultural, contribuya a la formación de ciudadanía reflexiva. Esta fase fue la que permitió seleccionar aquellos componentes encontrados en las emisoras analizadas, que servirían al objetivo final de formar ciudadanía reflexiva a través de contenidos de promoción cultural.

A partir de la elaboración de un modelo de ficha de contenido -agrupación estadística de las dos fichas anteriores-, que se aplicó a los programas caracterizados como aquellos que desarrollan contenidos culturales, se 
categorizaron los componentes que, en coherencia con la muestra de siete emisoras, serían de importancia para el modelo.

- Las herramientas: chats, videos, galerías, artículos y redes sociales.

- $\quad$ El formato magazín y las posibilidades que brinda de incluir en él otros formatos.

- Los géneros: entrevista, noticia, crónica, perfil e informe.

- Los productores staff de la emisora e invitados, llámense oyentes o expertos temáticos.

- Los principios de las emisoras de interés público para la línea editorial.

- Los contenidos culturales cuyo propósito sea poner en común diversidad de discursos y compartir memorias.

- Las experiencias personales y costumbres, por encima de los contenidos relacionados con algún arte.

Finalmente, la fase 3 de la metodología del proyecto es el modelo de radio ciudadana en Internet, es decir, el último capítulo del informe de la investigación "La Peña Cultural: modelo de radio ciudadana en Internet", por medio del cual se retomaron las características de la ciudadanía reflexiva y la promoción cultural abordadas en el marco conceptual de la investigación, toda vez que las variables necesarias, por lo menos para hablar de ciudadanía reflexiva, no se hallaron en la exploración etnográfica realizada en las dos primeras fases.

\section{Bases teóricas}

Fueron tres los marcos comprensivos abordados en esta investigación. Inicialmente se realizó un marco histórico que sirvió para percibir el fenómeno de la radio en Colombia (implementación, alcances y usos), puesto que ha sido, por excelencia, el medio de mayor acceso para la población y el de mayor aprovechamiento para diversidad de objetivos, como el de educar. Un segundo marco, el conceptual, tuvo el propósito de definir el campo de acción de la investigación, es decir, establecer las miradas de diferentes autores con respecto a la promoción cultural y la ciudadanía. Por último, el marco tecnológico, desde el soporte mediático, ayudó a comprender el mecanismo de funcionamiento de la radio en Internet y por qué su implementación podría tener alguna ventaja frente a la de otros medios de comunicación. 
La radio en Internet se tomó como el término atribuido a la transmisión y alojamiento de contenidos sonoros a través de streamcasting y podcasting de audio, características que permiten que cualquier persona en el mundo que tenga acceso a Internet pueda escucharlos y recuperarlos. Este tipo de radio utiliza elementos multimediales que facilitan la versatilidad de sus contenidos, no en vano "en esta nueva etapa de la comunicación, la radio se vuelve visible, adquiere la capacidad de una escucha asincrónica, bidireccional e interactiva, gana la posibilidad de ser archivada y recuperada, de volverse también texto, mejor dicho, hipertexto dejando el carácter volátil e intersticial que le es propio" (Menduni, citado por García González, 2010: 139). De ahí que sus audiencias, ya denominadas digitales, demanden ciertas características en el tratamiento de su información y constituyan, en palabras de Alcántara (2008) la modificación de los modos en que la arquitectura de transmisión de la información se organiza.

La promoción cultural, por otro lado, se encuentra ligada a las políticas públicas, reconociendo la importancia que estas tienen en la formación de ciudadanos con sentido de pertenencia y participativos de las apuestas artísticas y culturales de sus territorios en el marco de la diversidad, la memoria y la autenticidad. El modelo, resultado de este proyecto, se denomina "La Peña Cultural", dado que las peñas promueven el interés del pueblo por su propia cultura, propician espacios donde las personas puedan pregonar su arte, sus expresiones y fomentar el respeto por su identidad y sus antepasados", ${ }^{10}$ son lugares de encuentro para que los actores, promotores culturales y público en general disfruten de música, poesía, teatro, danza y otras expresiones artísticas, además de facilitar la puesta en común de tradiciones y costumbres que podrían aprovecharse para formar ciudadanía, una ciudadanía que rescate las particularidades de los individuos, pero, a su vez, fomente el consenso que en términos de tradición histórica y cultural esté presente en las memorias de los colombianos. En este sentido, se propendió por rescatar una promoción cultural del orden de tradiciones, costumbres y memorias que permitiera ponerse en diálogo con otros a través de la plataforma para construir un relato de nación, una que se compone de multiculturalidad e interculturalidad marcada por la globalización.

10 Definición consultada en: https://culturapalmares.wordpress.com/about/ 
En cuanto a la ciudadanía reflexiva, se abordó según el término acuñado por Carlos Thiebaut: "el ciudadano es, tiene que ser, un activo sujeto reflexivo, capaz de operar con diversidad de lógicas en distintos sistemas de acción: su concepción de lo público ha de estar marcada por una acendrada tolerancia; ha de adoptar una actitud reflexiva con respecto a lo que cree como condición para asumir sus responsabilidades" (1998: 169). Se trata de un ciudadano que está en constante construcción de acuerdo con los cambios sociales y culturales de los territorios, que indican que se debe entender que la ciudadanía se transforma y se compone de diversas miradas y narrativas, como afirma Ivic (2011: 12): "citizenship is composed of many narratives and different worldviews, it is a dynamic category, which continually changes, and cannot be reduced to membership or a territory". Sin embargo, esta ciudadanía debe asirse de una participación activa bajo el concepto de empoderamiento o creación neta de poder, que "incluye el requisito de la participación cívica, pero además comprende los elementos de educación, organización y de desarrollo político de la población" (Pineda Pablos, 1999). Esta participación puede hacer que la comunidad exprese sus particularidades en un intento por generar un discurso común, que no solo quede almacenado en un medio de comunicación, sino que también sea difundido para la apropiación de quienes accedan a él.

\section{Hallazgos preliminares}

\section{Plataforma, herramientas de participación, formatos y géneros}

La muestra total seleccionada y sometida a la primera ficha de contenido posee en sus plataformas alguna herramienta de participación (chats, videos, artículos, galería y redes sociales), y aunque la mayoría de las plataformas permiten la fácil identificación de las herramientas de radio en Internet, la ocasión de hallar todos estos elementos en una misma plataforma, con un diseño entrópico, hace que la consulta se dificulte y el oyente, en variadas ocasiones, suprima su deseo de participar.

El que las emisoras tengan las herramientas no garantiza su uso. De hecho, en ninguna de las plataformas se visualizó la participación de quienes oyen los programas. Los artículos no tienen intervención alguna, son 
escritos desde el staff para los oyentes y no ofrecen el deber ser de estar alojados en una web, es decir, no cuentan con el hipertexto del que tanto se habla en los debates de convergencia de medios. Los chats se encuentran vacíos de comentarios, lo cual es preocupante porque se pensaría que son el medio ideal para dejar las opiniones que les generan los programas a los oyentes. Los videos no se ven llevados a otros escenarios, aunque son elementos hipermediales que pueden ser embebidos o compartidos a través de sus url. Las fotografías tampoco son sometidas a opinión, hecho que permite pensar que no generan el suficiente malestar o beneplácito para usarlas como referencias en otros espacios de la red. Las redes sociales en su mayoría son del medio de comunicación, mas no del programa, lo que podría cohibir al oyente para participar, porque tendría que hacerlo acerca de la totalidad de la emisora y no, únicamente, del contenido en el que está interesado. ¿Será que los contenidos no mueven suficientemente el interés de las personas para abocarlos a hacer uso de las herramientas? ¿O será que el nivel de participación en Colombia sigue en el estado embrionario de la era moderna después de 23 años de vigencia de la constitución que reivindicó este derecho?

Seguidamente, el formato predominante para abordar contenidos culturales en las emisoras rastreadas es el magazín, lo que puede deberse a que este tipo de formato es flexible para el tratamiento de contenidos y se compone de los géneros que se desee. Las generalidades de los magazines encontrados son: una duración entre 30 y 60 minutos, dependiendo del programa, el uso de la entrevista y la música como hilos conductores del programa y el uso del cabezote y la cortina como elementos de identidad del programa.

Por lo visto, el documental, el dramatizado y el programa de opinión no son los favoritos a la hora de comunicar temáticas culturales, lo que es extraño a los ojos de quien investigó, puesto que los dos primeros pueden explotar mejor los recursos radiofónicos (voz, efectos de sonido, música y silencio).

El informativo es el aliado al momento de difundir agendas, programaciones y sucesos importantes acaecidos en las organizaciones. No en vano, cinco de los podcasts analizados se inscriben en este formato. No sor- 
prende encontrar que 13 de los 14 podcasts revisados combinen dos o más géneros periodísticos para narrar los contenidos, cuando seis de ellos se inscriben en el formato magazín.

A la luz de la promoción cultural que le preocupó a este proyecto, el tratamiento de la información a través de la entrevista, si se hace con el enfoque adecuado, puede mover fibras, incitar a la participación desde la experiencia y el saber heredado a partir de la interculturalidad que hay en Colombia. No obstante, esto no sucede en la muestra, puesto que la entrevista implementada exhibe una información impuesta por el medio y sus productores.

\section{Productores y prosumidores}

Teniendo en cuenta que esta radio en Internet se piensa como menos compleja para producirse, con herramientas más amables como las que se pusieron en común en la pregunta de canales de participación, es un desconcierto encontrar que los oyentes no son los protagonistas y no aportan a la producción de los contenidos de estos programas. El prosumidor, como se plantea en la teoría -un receptor y también productor de contenidos-, no se evidenció en la muestra analizada; es decir, el oyente que adquiere carácter de realizador no se encontró, lo que fue preocupante para el modelo, que tuvo que plantearse esta figura desde supuestos conceptuales llevados comparativamente a la práctica.

El modelo de producción hallado es igual al de las emisoras análogas (el 90\% de la muestra es de emisoras análogas llevadas a la web), en tanto el staff de cada emisora es el responsable de que los contenidos salgan al aire. Los expertos son una parte importante en el desarrollo de las temáticas, no obstante, aparecen otros productores, que experimentan sobre la marcha y que toman la emisora como un laboratorio de aprendizaje continuo y colaborativo: los estudiantes de comunicación de las emisoras universitarias. Ahora, ¿se puede llamar a estos estudiantes "prosumidores"? La reflexividad en el marco de la acendrada tolerancia ${ }^{11}$ de la que habla Thiebaut se pone a prueba en estas plataformas, cuya función como espacios

11 La acendrada tolerancia implica aprender algo en el diálogo con el otro. 
públicos sería la de propiciar la adhesión del ciudadano a su cultura a través de la participación en ellas.

\section{Las emisoras y sus principios}

Las siete emisoras sometidas a los instrumentos se pueden clasificar, según la Resolución 415 de 2010, como emisoras de interés público, por eso, se rescataron para el modelo algunos de los principios de esta norma:

1. Reconocer y respetar los derechos fundamentales del ser humano. Especialmente, el Artículo 19 de la Declaración Universal de los Derechos Humanos, que establece la libertad de expresión y opinión.

2. Dar la debida importancia a los mensajes que reconozcan la diversidad en todas sus formas: cultural, sexual, racial, política u otra. Promover espacios de participación que muestren la diferencia como algo positivo.

3. Dar participación a las personas, sin discriminación o prejuicio de ningún tipo.

4. Consultar varias fuentes y establecer su idoneidad, con el propósito de lograr información objetiva.

5. Tomar posición en casos de discriminación, violación, injusticia o violencia de cualquier tipo.

6. No promover ni incentivar la violencia bajo ninguna de sus formas.

Fue gratificante comprobar que estos principios son una ruta de navegación que va en concordancia con lo que se necesitaría a la hora de producir, compartir y retroalimentar las plataformas en cuanto a promoción cultural en Colombia. Algunos de ellos reafirman la diversidad, el respeto y la libertad como características primordiales para el desarrollo de la participación en el marco de la democracia, en tanto reconocen y respetan los derechos fundamentales del ser humano, promueven el acceso a los contenidos por parte de cualquier comunidad, postulan la importancia de que los mensajes emitidos reconozcan la diversidad en todas sus formas y no incentivan la violencia y discriminación en relación con raza o grupo étnico alguno, bajo ninguna de sus formas. 


\section{Promoción cultural, el contenido que prevalece}

Efectivamente, todos los programas cumplieron con las características de dedicarse a divulgar la cultura, aunque también tratan temas de sociedad, arte, política, educación y entretenimiento. El tipo de promoción cultural caracterizado corresponde a poner en común datos, personajes, grupos étnicos y lugares de Colombia, además de fomentar y difundir las actividades que realizan las universidades y otros espacios que, de por sí, ya tienen una asociación con lo cultural, específicamente con el arte, la música, el teatro y la danza. La promoción cultural hallada no es, en su totalidad, una promoción como la define la Ley 397 de 1997: que difunde el "conjunto distintivo de rasgos espirituales, materiales, intelectuales y emocionales que caracterizan a los grupos humanos y que comprende, más allá de las artes y las letras, modos de vida, derechos humanos, sistemas de valores, tradiciones y creencias" y que es exactamente la que le interesó a este modelo para su construcción, más aún si quienes la producen no son sus protagonistas. La promoción ideal, definida a partir del marco conceptual, es aquella en la que tengan cabida los saberes populares, las experiencias personales, tradiciones y costumbres compartidas en una plataforma como la radio en Internet, con el propósito del diálogo y el consenso en la diversidad y la pluralidad.

Hay que tener en cuenta que la diversidad de discursos identificados fue la de los expertos, el staff y los estudiantes que produjeron los programas, no la de los oyentes, y que la memoria y la autenticidad individuales son características que darían cuenta de la diversidad de los sujetos en Colombia. Puestos en diálogo en la plataforma multimedial, estos elementos reivindicarían la autonomía de un ciudadano reflexivo en el marco de la acendrada tolerancia.

\section{La participación}

El proyecto se preguntó por los productores desde una mirada no especializada y con un saber propio que pueden compartir sus opiniones por medio de los elementos de una plataforma hipermedial que ha sido puesta para su aprovechamiento, es decir, la opinión de los oyentes, que finalmente no se evidenció. 
Es apenas lógico que si no hubo participación de oyentes y las únicas opiniones expresadas fueron las de algunos productores, tampoco se visualizara el uso del hipertexto. Este tipo de texto permite compartir la información en otros espacios de Internet para asentir o negar lo que propone temáticamente el programa de radio, es decir que, como afirma García González (2010), debido a su estructura no secuencial, permite crear, agregar, enlazar y compartir información de diversas fuentes por medio de enlaces asociativos. Por sus características, el hipertexto sería la herramienta ideal para argumentar opiniones en Internet, porque no se trata solo de compartir los contenidos de la plataforma radial, sino también de controvertirlos citando otros contenidos que se pueden consultar en la web.

La ausencia de participación de los oyentes implicó que no se tuviera material para el análisis del diálogo, el consenso y la movilización en ellos. De hecho, la falta de participación es la expresión misma de la falta de movilización frente a los temas que estos programas trabajaron. Es inquietante que las temáticas trabajadas, aunque enmarcadas en el área cultural, no movilizaran la opinión de quienes escuchan los programas; sería de utilidad, como proyecto alterno o de seguimiento a este, identificar los niveles de audiencias virtuales y análogas que tales programas registran y cómo lo hacen, para verificar, contactando a dichos oyentes, por qué no intervienen de manera pública ni manifiestan sus opiniones con respecto a los contenidos que les son ofrecidos. Esto ayudaría a definir si es falta de interés, poco conocimiento acerca del manejo de las herramientas o, simplemente, que esos contenidos no son acertados para motivarlos a ejercer su derecho a la participación, como sería lo adecuado a la hora de hablar de ciudadanía reflexiva.

\section{El ciudadano reflexivo}

No fue posible hablar de una adhesión reflexiva porque no se tuvo la evidencia de participación en la plataforma, de las tradiciones, saberes populares, costumbres y rituales de la cultura en la que se encuentra inmerso el escucha de estos contenidos, siendo la adhesión reflexiva una de las características fundamentales para el ciudadano reflexivo, porque en ella se encuentra el peso de una relación identitaria con el contenido que se produce y transmite. 
Esa adhesión debe ser interpretada a partir de los mecanismos de participación del medio de comunicación y los usos que les dan los oyentes, debido a que, finalmente, la plataforma es el soporte para evidenciar "el reto de asumir la heterogeneidad como un valor articulable a la construcción de un nuevo tejido de lo colectivo" (Martín Barbero citado por Sierra Gutiérrez, 2003: 179). En otras palabras, la adhesión reflexiva es el engranaje que permite la relación directa entre el contenido del programa y la identidad de la que se siente parte el oyente. En el caso de las emisoras revisadas con herramientas multimediales, solo es posible visibilizar la adhesión reflexiva cuando el oyente se anima a participar y dejar evidencia de su pensamiento con respecto al contenido que ha recibido.

\section{Conclusiones}

La ciudadanía, tal y como la propone Carlos Thiebaut, no se vio activa en la muestra de emisoras seleccionada. La variable participación, que es por medio de la cual se puede analizar el tipo de ciudadanía que forman estos programas, tampoco es visible, y su ausencia es un indicador que fortalece la posición en la que se encuentra Colombia como estado al hablar de este concepto nacido en la modernidad. Queda la sensación de que esta es una nación a medias, un estado inacabado donde, a pesar de existir un marco jurídico para garantizar que los espacios públicos sean democráticos y participativos, estos espacios no están siendo aprovechados por sus habitantes para sentar sus posiciones acerca de diversas temáticas. En este caso, la ciudadanía se estaciona en la figura del individuo perteneciente a un territorio, con mayoría de edad y que tiene algunas herramientas como el voto para activar su papel como ciudadano, es decir, en una ciudadanía participativa mas no reflexiva.

Ejercer la autonomía supone ejercer las capacidades crítica y reflexiva, de autorregulación y autorrepresentación que tienen los individuos, ciudadanos reflexivos, en la esfera pública. En otros momentos del proyecto, estas capacidades se vieron desiertas por la falta de participación de los oyentes, los discursos autónomos no tuvieron lugar en la muestra de programas y, por eso, se puede hablar de un abandono de la "capacidad de los sujetos de elegir y direccionar conscientemente su accionar, relacionarse 
con una posición propia, hacerse responsables de sus decisiones" (Plan de Desarrollo Cultural de Medellín, 2011). ¿ Será que este abandono es a propósito? ¿No participar se convierte en una manera de manifestar su opinión con respecto a los contenidos de los programas que se analizaron?

Se debe enfatizar el hecho de que para evidenciar los atributos del ciudadano reflexivo debe evidenciarse una participación en las plataformas. La acendrada tolerancia, como lo indica (Thiebaut, 1998: 275), solo requiere que pensemos que "algo puede ser aprendido en el diálogo y en la interacción misma”. Este diálogo e interacción no se presentó en las herramientas dispuestas para ejercer la participación. Quedan entonces varias interrogantes: ¿es suficiente con la plataforma para garantizar la participación? ¿Los contenidos de estas radios no mueven las fibras del pensamiento de quienes los oyen? ¿Quienes escuchan estos programas sí tienen la oportunidad de aprender algo en el diálogo? ¿O es una transmisión de contenidos que al azar podrían intervenir en los conocimientos de los oyentes?

La capacidad reflexiva requiere de ciudadanos que expresen sus ideales e intereses, organizándolos, articulándolos y negociándolos a nivel social (Leal González, 2008: 136). De acuerdo con lo que enuncia Thiebaut en su obra, esta es la capacidad de todo ciudadano para pertenecer y sostener, aunque sea de manera crítica, sus creencias, normas y procedimientos, y ese trata también de modificarlas, alterarlas. No se pudo acceder a opiniones de oyentes en las que se vieran confrontaciones, diálogo y conceso para determinar las maneras en las que esos oyentes pudiesen ejercer dicha capacidad. Siguen siendo los productores e invitados a los programas quienes tienen el protagonismo en cuanto a la participación; el oyente no participa, es decir que no ejerce la característica fundamental para la definición del ciudadano, sobre todo del ciudadano reflexivo.

La Constitución de 1991 es la carta que abrió variedad de posibilidades para rescatar el principio de participación por medio del cual "el ciudadano deja de ser sujeto pasivo para convertirse en ciudadano activo, portador y legitimado para ejercer jurídicamente intereses sociales, colectivos o difusos" (Sánchez Torres, 1994: 96). Los ciudadanos son sujetos diversos, con 
influencias multiculturales e interculturales si se quiere, reconociendo la sociedad plural que conforma a este país, como se menciona en el artículo 70: "la cultura en sus diversas manifestaciones es fundamento de la nacionalidad. El Estado reconoce la igualdad y dignidad de todas las que conviven en el país". Sin embargo, no parece ser suficiente abrir estas posibilidades; tampoco el hecho de ampliar el espectro de participación a otras esferas que, aunque públicas, no habían sido tenidas en cuenta en otros momentos históricos de la ciudadanía -como los medios de comunicación-. Aunque no se registran opiniones que permitan visualizar la sociedad plural a la que pertenecen los oyentes, los programas, con las temáticas que trabaja cada uno, sí dan cuenta de una sociedad multiétnica, pluricultural, con comunidades negras, raizales, indígenas, etc.

La cultura es un tema que, en medio de su amplitud, puede mostrar el camino de la identidad y cómo esta es forjada en el seno de unas prácticas y memorias de toda índole: sociales, políticas, económicas. El modelo debió, entonces, cerrar su espectro para que la relevancia se la lleve la promoción cultural desde la informalidad del discurso individual que, en el diálogo, aportara al relato común. A partir de esta metodología, se dejarían de producir los discursos y memorias compartidos desde la visión de unos pocos, de quienes producen y conocen a cabalidad las dinámicas del medio, para crear discursos y memorias recolectadas en la esfera pública como evidencias de las tradiciones, costumbres e historia de un pueblo que aún no reconoce su adhesión.

Los contenidos culturales que se hallaron en la muestra están direccionados hacia agendas informativas, informaciones generales de personajes, momentos y lugares históricos y algunos saberes que por información general deberían ser heredados por todo ciudadano colombiano, pero no son promoción cultural como se encuentra consignada en el marco conceptual. La autenticidad, diversidad y memoria son características propias de la promoción cultural, más aún si su finalidad es formar ciudadanía. Promover el sentido de identidad que fomenta la participación desde de la complejidad individual es reconocer que "ninguna cultura podrá sobrevivir en condiciones de creciente reflexividad si no es por medio de la consciente y reflexiva adhesión de los miembros de esa cultura" (Thiebaut, 1998: 138). 
La radio en Internet fue encontrada a medias, es decir, se hallaron muchas emisoras que transmiten en directo y no alojan podcasts en sus plataformas; solo una muestra pequeña de emisoras con un gran porcentaje de mudanza de contenidos análogos a la web cumplió con ambos requisitos. No obstante, y a pesar de lo multimedial que pueda ser, la nula participación podría responder a la brecha digital que presentan países como Colombia, cuyas problemáticas de violencia, de pobreza y de poca o nueva normatividad para participar no han permitido la consecución de los medios para que las personas se animen a hacerlo. Entonces, ¿cómo es que otros medios, como los abordados en el marco histórico, han logrado semejantes propósitos? Se convierte este en un tema de culturización, de saber que ahora las libertades están servidas en la mesa y que estas hacen parte del proceder del ciudadano. Es una tarea que, como aquella de recuperar un relato común, tal vez lleve más tiempo del esperado.

La radio en Internet no se destaca como un medio de comunicación que, con todas las herramientas instaladas, genere por sí solo la necesidad de participar y construir en conjunto. Parece que hace falta algo más que la plataforma y sus mecanismos para movilizar a las personas, a sus escuchas, para que se hagan prosumidores de contenidos. Tal vez se hace indispensable, como en los ejemplos hallados en el marco histórico, establecer alianzas entre lo análogo y lo digital -con medios impresos y audiovisuales- para el reconocimiento de los elementos en Internet que permitirían la participación, además de un refuerzo en la instrucción del uso de tales elementos. Adicionalmente, las herramientas multimediales tuvieron un apartado específico en el modelo a manera de instructivo para aportar a su propósito; este "modo de uso" establecido en el modelo, en especial de la herramienta redes sociales, podría aclarar su funcionalidad y servir para que el oyente tenga claridad de cómo participar por medio de ella, además de que su opinión quede contextualizada en la temática específica a la que se refiera, es decir, que la emisora pueda tener, por ejemplo, una fanpage y que el programa, con su enfoque temático, tenga un grupo adherido a esa fanpage.

La línea editorial, los fundamentos de estilo y la misión del modelo de radio ciudadana se construyeron de manera específica, clara y concisa, para que el manejo de la información no pueda perderse en una explica- 
ción mal dada. Esta parte del modelo, siendo la base sobre la que se erige lo demás, tuvo que establecer los instructivos de las herramientas anteriormente mencionadas y toda la ruta sobre la cual navegará la parte formal y temática de las producciones sonoras para Internet.

En definitiva, no se hallaron los discursos autónomos, las adhesiones y capacidades reflexivas, y mucho menos las acendradas tolerancias. En una participación nula no podría caber el reconocimiento de identidades y de la diversidad o la defensa y promoción de derechos, porque las únicas voces que aparecen son las que proponen el tema a debatir. Los contenidos se sirven en una mesa pública a la que los oyentes pueden tener acceso para debatirlos, complementarlos, rechazarlos o afirmarse en ellos, y no lo hicieron. Es desconcertante encontrarse con que la participación, aun después de 23 años de vigencia de la Constitución de 1991 en Colombia, ha sido poco apropiada por los ciudadanos-por lo menos, por los oyentes de estos contenidos-. Por otro lado, el hecho de afirmar que estas plataformas no forman ciudadanos reflexivos hizo aún más exigente la propuesta de crear un modelo de radio ciudadana en Internet que, a través de la promoción cultural, contribuya a la formación de ciudadanía reflexiva. Este fue un reto que se asumió desde los aportes de los teóricos trabajados en el marco referencial sobre promoción cultural, radio en Internet y ciudadanía reflexiva; además, desde la perspectiva formal que dejó la ficha de contenido 1 acerca del abordaje de tales contenidos, reto asumido con responsabilidad y entusiasmo.

\section{Referencias}

Alcántara,J. (2008). La Sociedad de Control. Privacidad, propiedad intelectual y el futuro de la libertad. Barcelona: El Cobre Ediciones.

Constitución Política de Colombia (1991). Artículo 70. República de Colombia.

García González, A. (2010). Radio digital e interactiva. Formatos y prácticas sociales. Revista Icono14, 15, 133-146. Recuperado de: file://C:/ Users/USUARIO.CATALOGO2PBSAP.000/Downloads/Dial- 
net-RadioDigitalEInteractiva-3301330.pdf (Fecha de consulta: noviembre 16, 2011).

Ivic, S. (2011). The postmodern liberal concept of citizenship. Probing the Boundaries, 64, 3-18.

Leal González, N. (2008). Participación ciudadana y la construcción de ciudadanía. Cuestiones Políticas, 24.

Pineda Pablos, N. (1999). Tres conceptos de ciudadanía para el desarrollo en México. México.

Plan de Desarrollo Cultural de Medellín 2011-2020 (2011). Medellín: Secretaría de Cultura Ciudadana.

Rodríguez Barba, F. (2009). The importance of the Convention on the Protection and Promotion of the Diversity of Cultural Expressions adopted by UNESCO and its impact on Mexican cultural policies. CONfines, 5, 23-37.

Sánchez Torres, C. (1994). Participación ciudadana en Colombia. Bogotá: Biblioteca Jurídica.

Sierra Gutiérrez, L. I. (2003). Globalización, multiculturalismo y comunicación. En Villadiego Prins, M. \& Pereira González, J. M. Comunicación, cultura y globalización: memorias. Bogotá: CEJA.

Thiebaut, C. (1998). Vindicación del ciudadano: un sujeto reflexivo en una sociedad compleja. Barcelona: Paidós.

Uribe de Hincapié, M. T. (2001). Nación, ciudadano y soberano. Medellín: Corporación Región.

Valderrama, C. E. (2004). Medios de comunicación y globalización: tensiones de la política, las identidades y la educación. Medellín: Nómadas. 